\title{
CARACTERIZACIÓN DE LA FORMA, TAMAÑO Y FUNCIÓN DE LAS VASIJAS ORDINARIAS DE PUERTA DE CORRAL QUEMADO (DPTO. DE BELÉN, PROV. DE CATAMARCA)
}

\author{
María Emilia Iucci \\ Laboratorio de Análisis Cerámico. Facultad de Ciencias Naturales y Museo. \\ Universidad Nacional de la Plata emiliaiucci@yahoo.com.ar
}

Presentado el: 13/04/2009 - Aceptado 20/07/2009

\section{Resumen}

En este trabajo se analiza cerámica ordinaria tardía de la localidad de Puerta de Corral Quemado (Dpto. de Belén, Prov. de Catamarca), hallada tanto en una serie de entierros dispersos como en las estructuras excavadas en El Molino, un poblado arqueológico adscrito al Período de Desarrollos Regionales del Noroeste argentino (1100 - 1480 D.C.).

Se parte de la premisa de que las elecciones técnicas que realicen los ceramistas durante el proceso de manufactura, en este caso específicamente en cuanto a la forma y el tamaño, permitirán elaborar una vasija que favorecerá ciertos usos. De esta manera, el análisis de la forma y el tamaño constituye evidencia indirecta para establecer hipótesis acerca de las funciones para las que las vasijas resultaban particularmente adecuadas. En el presente trabajo se realiza una descripción de las formas y tamaños de las piezas fragmentarias y completas, y se sugieren una serie de hipótesis acerca de sus posibilidades funcionales.

A través del análisis de las vasijas ordinarias pudimos observar una amplia variedad de formas y tamaños, al mismo tiempo que una regularidad en la forma de ciertos tipos de piezas. Con respecto a las funciones inferidas, se halla una probable distinción entre aquellas relacionadas con la esferas doméstica y funeraria.

Palabras clave: Cerámica ordinaria - forma - función de vasijas

\begin{abstract}
We analyze in this paper late ordinary ceramics from Puerta de Corral Quemado (Dpto. de Belén, Prov. de Catamarca), found in scattered burials and in the excavated structures from El Molino, an archaeological site in Argentinean Northwest which belongs to Regional Developments Period (11001480 D.C.).

Technical elections related with shape and size during the manufacture process allow potters to make suitable vessels for specific uses. Thus, the shape and size are indirect evidences to make hypothesis about which functions were the vessels appropriated for. In this paper we make a description of shape and size of fragmentary and complete pieces, and present some hypothesis about its functional possibilities.

In the analyzed ordinary vessels we observe a wide variety of shapes and sizes, and a tendency to morphological regularity in certain types of pieces. Related to the inferred functions, we found probable differences between vessels from the domestic and the funerary sphere.
\end{abstract}

Key words: Ordinary pottery - form - vessel function. 


\section{Introducción}

La cerámica comúnmente llamada ordinaria ha sido uno de los ítems menos abordados en la literatura sobre cerámica arqueológica del Noroeste argentino. Ya sea por la importancia que ha tenido la cerámica fina a la hora de realizar adscripciones cronológicas o culturales y la atención dedicada a sus aspectos decorativos o simbólicos, como por la escasa presencia de vasijas ordinarias completas en las colecciones museológicas, o la fragilidad de sus pastas porosas que dificulta la tarea de remontar piezas enteras en los contextos domésticos, este tipo de alfarería ha sido habitualmente relegado. Sin embargo, constituye un material de ineludible importancia para indagar sobre las prácticas domésticas y funerarias del pasado, y que complementa el estudio de la cerámica fina desde los puntos de vista de la organización de la producción, la circulación y el uso.

La cerámica ordinaria exhumada en la localidad de Puerta de Corral Quemado (Prov. de Catamarca) es un ítem muy bien representado dentro del conjunto arqueológico existente. Por un lado, los 970 fragmentos con los que contamos constituyen el material más abundante de las estructuras excavadas en el sitio de mayores dimensiones del área, conocido como El Molino, un sitio adscrito por González y Cowgill (1975) a la cultura Belén del Período Tardío (1100-1480 D.C.). Por el otro, existen una serie de entierros situados en los alrededores del sitio, excavados durante la década de 1920 en el marco de las expediciones financiadas por Benjamin Muñiz Barreto, en los cuales se registraron alrededor de 30 contenedores ordinarios utilizados como urnas o formando parte de los ajuares funerarios (Wiesser y Wolters 1924). De esa cantidad hemos podido recuperar 6, que son los analizados aquí.

En este trabajo se caracterizan la forma y el tamaño de las vasijas ordinarias fragmentadas y completas del sitio y alrededores, y se presentan algunas posibilidades funcionales de las piezas en tanto contenedores, es decir, en un rol en el que se vuelven necesarias ciertas características morfológicas y tecnológicas para un adecuado desempeño durante su uso. En particular, se apunta a establecer hipótesis acerca de la relación entre la forma, el tamaño y la función de estas de vasijas. Para ello se tomarán principalmente los conceptos enunciados en la síntesis de Rice (1987).

Es necesario aclarar que tanto la discriminación de la cerámica ordinaria bajo una categoría distinta de la fina, como el uso de un término específico para designar a esta categoría, son problemas que ya han sido abordados ( $1^{\circ}$ Convención Nacional de Antropología 1966, Rice 1987, Zagorodny y Balesta 1999, Marchegiani y Greco 2007) y que aún no encuentran consenso. En este trabajo se toma el término "ordinario" para evitar las connotaciones funcionales que llevan implícitos otros términos, tales como "utilitario" o "doméstico". Por otro lado, si bien el uso de esta categoría implica englobar a una gran diversidad de formas, pastas y características tecnológicas, permite realizar una separación operativa de la cerámica fina con el fin de estudiarla. De esta manera, tomamos el término "ordinario" en un sentido descriptivo para seleccionar aquellas vasijas y fragmentos que tienen pasta deleznable, inclusiones sobresalientes, acabado de superficie alisado en forma despareja, y que en general no están tipificados en categorías morfológicas y decorativas como pueden ser los tipos cerámicos Belén, Santa María, etc. 


\section{Forma, tamaño, función, uso}

A partir de observaciones etnográficas y de trabajos de síntesis, distintos autores (Rice 1987, Sinopoli 1991, Skibo 1992) plantean que las aproximaciones al estudio sobre cómo se utiliza la cerámica pueden ser realizadas desde dos puntos de vista: el que considera para qué fue diseñado un artefacto, y el que se basa en cómo éste fue realmente utilizado. El primero indica un marco general de las funciones en las que las vasijas pueden haber resultado particularmente eficientes, y el segundo provee evidencia directa de uso.

Las evidencias directas de uso pueden analizarse a través de una serie de análisis que brindan información sobre lo que Skibo (1992) llama procesos de adición, entre los que se encuentran los depósitos de carbón y los residuos dejados por el contenido de la vasija, y procesos de desgaste, que incluyen las marcas de abrasión y el desgaste físico o químico. El contexto de recuperación de los recipientes también provee información sobre el uso real que tuvo la vasija, por lo menos en el momento inmediatamente previo al que pasó a formar parte del registro arqueológico (Rice 1987).

La determinación de la función se basa en que las elecciones que realiza el ceramista durante el proceso de manufactura en cuanto a la forma, tamaño, materias primas y tecnología en general, son posibilidades que tiene para crear vasijas que desempeñen en forma adecuada las actividades a las que serán destinadas (Rice 1987, Sinopoli 1990, Skibo 992, Orton et al. 1997). A partir de esta premisa se considera que las características de la forma, tamaño y tecnología favorecerán ciertos usos, y por lo tanto constituyen evidencia indirecta para establecer hipótesis acerca de las funciones para las que las vasijas resultaban particularmente adecuadas.

Rice (1987) menciona que en general cada tipo de comida u ocasión de preparación puede requerir un recipiente o un conjunto de recipientes apropiados dentro de un ajuar doméstico. Distintos trabajos etnográficos (Skibo 1992, Menacho 2001) llevan más allá esta afirmación, indicando que algunas sociedades utilizan cierto tipo de vasijas exclusivamente para usos particulares. Sin embargo, estos mismos trabajos observan también que muchas veces y por distintos motivos se reemplaza un tipo de vasija por otro, o se reutilizan una vez cumplido el primer propósito (Skibo 1992, Orton et al. 1997). Es por ello que una aproximación adecuada a la utilización de las vasijas debe considerar tanto los aspectos de diseño como las evidencias directas de uso mencionadas arriba en forma integrada. En este trabajo, y como una aproximación preliminar a los estudios de uso de los materiales cerámicos de Puerta de Corral Quemado, se tomará el diseño de la forma y el tamaño para establecer relaciones con las funciones que los distintos tipos de vasijas podrían desempeñar en forma eficiente.

Las categorías funcionales que se tomarán son las tres que propone Rice (1987): almacenamiento, procesamiento y transporte de sustancias. Teniendo en cuenta estas tres categorías, la autora enumera una serie de especificaciones que entran en juego en la relación forma-diseño: si los contenidos son líquidos o secos, si son calientes o fríos, si se aplicará calor durante su uso, la frecuencia de movimientos para el acceso a los materiales dentro o fuera del contenedor, la duración de los episodios de uso, la distancia del traslado, si la mano o un utensilio será puesto dentro del contenedor, si la actividad es observada, cuál es el volumen de los contenidos, etc. A partir de la combinación entre las tres categorías 
funcionales y las especificaciones, menciona 21 categorías de uso (almacenar líquidos, tostar, hervir, mezclar, servir, acarrear agua, etc.). Smith (1988) estableció una clasificación de 14 usos partiendo de especificaciones similares.

Las principales propiedades de la forma que el ceramista puede manipular para que las vasijas se adecuen a esas funciones son la capacidad, la estabilidad, la accesibilidad y la transportabilidad (Rice 1987). La capacidad depende principalmente de la forma y el tamaño de la vasija. La estabilidad, definida por la autora como la resistencia de la vasija a ser volcada, tiene como mejores indicadores a la ubicación del centro de gravedad de la vasija y a la relación entre base y altura. El acceso al interior estará determinado por el tamaño del orificio y la altura total de la pieza. La transportabilidad, o la facilidad para mover una vasija, será consecuencia del tamaño, una cualidad comúnmente llamada agarre o prensilidad, y, sobre todo, de la presencia de elementos tales como asas y rebordes que posibiliten la realización de palanca, eviten el deslizamiento y protejan de las altas temperaturas.

Otras propiedades de la forma que menciona Rice (1987) intervienen en la ejecución eficiente de la pieza de ciertas tareas particulares. La existencia de ángulos agudos produce calentamientos desparejos y stress térmico, producto del uso sobre el fuego, que podrían provocar la rotura de la vasija, por eso son preferibles las vasijas de forma simple o contorno inflexionado. El cierre de la vasija o la posibilidad de que sea cerrada con una tapa son importantes para la función de almacenamiento, dado que evitan el derramamiento o la pérdida de contenidos. El grosor de las vasijas está relacionado con distintas posibilidades de uso: las vasijas livianas son más adecuadas para su traslado, especialmente si los contenidos son líquidos y deben transportarse a través de distancias largas. Por otro lado, las paredes delgadas conducen mejor el calor, cocinan más rápido y ahorran combustible. Sin embargo pueden ser deseables paredes gruesas para el almacenamiento, dado que incrementan la estabilidad y preservan la humedad dentro o fuera del recipiente. Además, durante el procesado son más resistentes a los golpes para batir, agitar o mezclar.

El tratamiento de superficie también es importante para el desempeño de determinadas funciones. Una superficie pulida o bruñida puede retardar la penetración de líquidos a la vasija, reduciendo la permeabilidad en vasijas de procesamiento y almacenamiento, y facilitando la limpieza de los recipientes. Sin embargo, para las funciones de traslado una superficie áspera será la más adecuada, dado que facilita el levantado y el acarreo. Por último, el tratamiento de superficie también afectará las propiedades térmicas de una vasija, dado que un exterior desparejo tiene mayor superficie para absorber calor o evaporar líquidos, adecuándose mejor a las funciones que impliquen exposiciones de sustancias al calor (Rice 1987).

\section{Universo de estudio}

El universo de estudio abordado está formado por dos grupos de materiales clasificados como ordinarios bien delimitados: por un lado, los fragmentos de las estructuras excavadas en el sitio El Molino; por el otro, las vasijas completas procedentes de Puerta de Corral Quemado, donde se encuentra ubicado el sitio, pertenecientes a la Colección Muñiz Barreto del Museo de La Plata.

El poblado arqueológico El Molino se encuentra en el sector septentrional del Valle de Hualfín, al S.O. de la actual localidad de Puerta de Corral Quemado, Provincia de Catamarca, en las coordenadas $27^{\circ} 13^{\prime} 49,4^{\prime \prime} \mathrm{S}$ y $66^{\circ} 566^{\prime} 38,6^{\prime \prime} \mathrm{W}$, a una altura de 1932 metros sobre el 


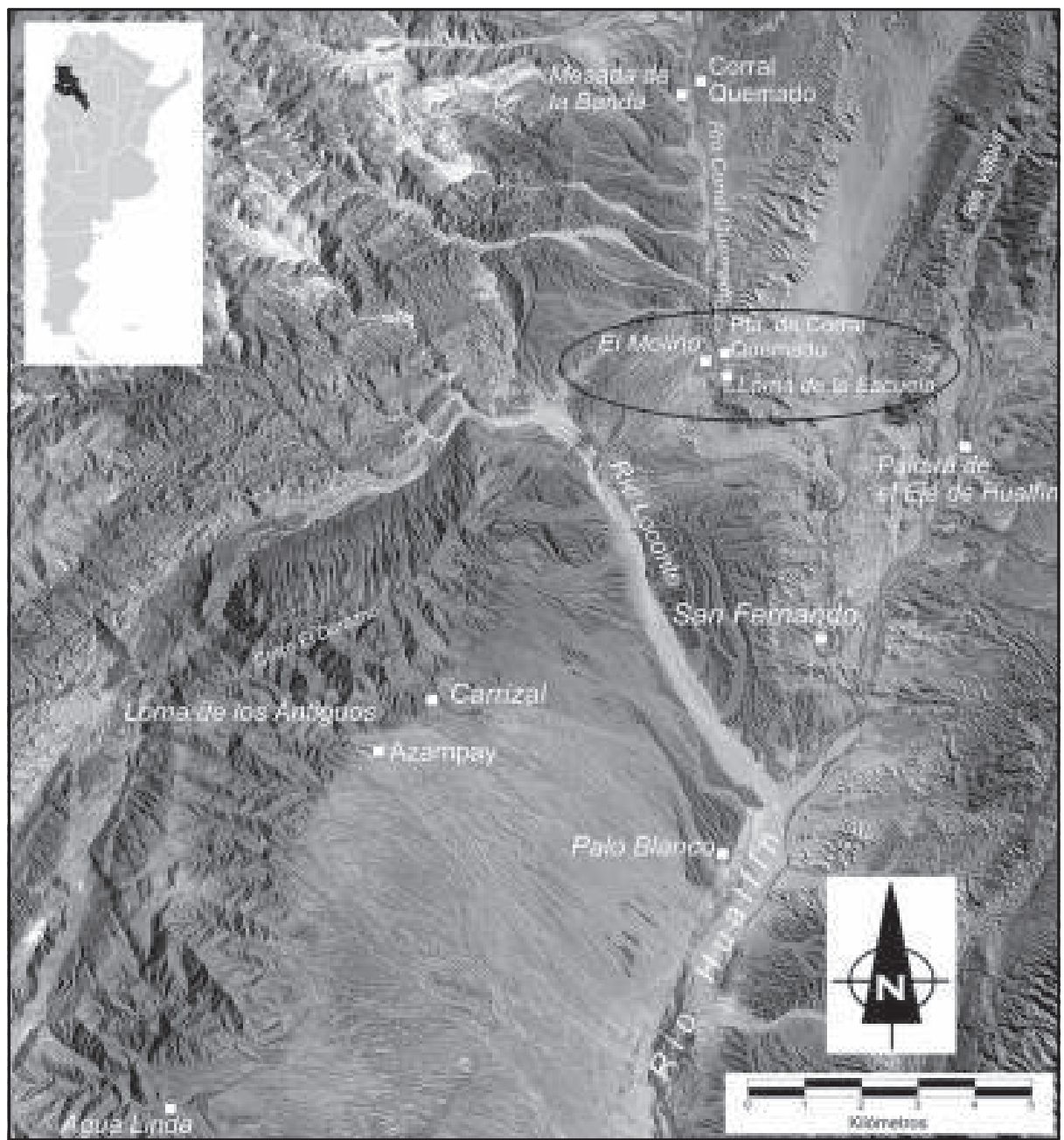

Figura 1. Mapa del centro y norte del Valle de Hualfin. En círculo, la zona de Puerta de Corral Quemado.

nivel de mar, en la orilla Sur del Río Corral Quemado (Figura 1). Fue caracterizado por Sempé (1999) como un pueblo aglomerado sobre cerro, defendido con murallas. Está formado por alrededor de 110 estructuras de piedra, al menos 90 cerradas, y otras que forman pequeños muros de contención y murallas. Estas estructuras se encuentran emplazadas sobre una lomada de aproximadamente 70 metros de altura sobre el terreno circundante, con una serie de desniveles en los que se agrupan las construcciones. A diferencia de muchos sitios del valle, que se caracterizan por estructuras homogéneas y poco densas (Wynveldt 2007, Wynveldt y Balesta 2009), las de El Molino presentan diferentes modalidades constructivas y están dispuestas de manera aglomerada. Estos trabajos han mostrado asimismo la mayor cercanía de los sitios caracterizados como Belén en el Valle, con El Molino entre ellos, a los momentos incaicos que a las primeras etapas del Período de Desarrollos Regionales. 
En 1969, A. R. González realizó recolecciones superficiales y excavó tres estructuras arqueológicas, en las cuales recuperó material cerámico, lítico y óseo ${ }^{1}$. Entre el material cerámico, además del ordinario analizado en este trabajo, se recuperaron fragmentos de pucos y tinajas (sensu Wynveldt 2007) Belén y Santa María. Asimismo, debajo del piso de la Habitación 98, se halló la única pieza cerámica entera (González 1974), clasificada como "Santa María piriforme". González realizó un fechado sobre carbón de 930 AP +-70 (Tx 989) (González y Cowgill 1975)².

Las estructuras excavadas en ese momento fueron las "Habitaciones" 68, 98 y 110, con 285,602 y 83 fragmentos clasificados como ordinarios respectivamente. Los materiales no están acompañados del registro de los procedimientos y técnicas seguidos durante la excavación, solamente se cuenta con las aclaraciones rotuladas en los fragmentos de la procedencia del piso, relleno o trincheras, y una ficha que separa algunos fragmentos de la Habitación 110 como "fragmentos de urna y puco de enterramiento" y con una etiqueta de caja que indica "materiales óseos encontrados al lado de tapa de urna" y "encontrados dentro de urna".

Las piezas completas de la Colección Muñiz Barreto del Museo de La Plata provienen de los relevamientos y excavaciones de tumbas dispersas conducidas por Wladimiro Weisser en 1924, quien además de recolectar los materiales arqueológicos, confeccionó un plano del sitio y localizó otras ocupaciones en la zona. El diario de campo de Weisser (1924), el plano y los cuadernos de su ayudante Wolters (1924) acompañan a la Colección. En los cuadernos se encuentran registrados los croquis de las tumbas junto con la cantidad y estimación etárea de los individuos enterrados, y la forma y posición de las piezas arqueológicas halladas en ellas. Asimismo, se puede rastrear la localización aproximada de los entierros.

En la zona de Puerta de Corral Quemado los miembros de la expedición encontraron alrededor de 30 piezas ordinarias que, según la información de las cuadernos, se ubican al pie y en las proximidades de El Molino, en la zona correspondiente a Agua Verde, en una zona "al sud de la Puerta de Corral Quemado" (Wolters 1924), y un conjunto ubicado en un sector próximo a la localidad de Hualfín descrito como "de Corral Quemado hacia el oeste del Cerro Colorado" (Figura 2). Algunas de estas piezas se hallaban fracturadas y se dejaron

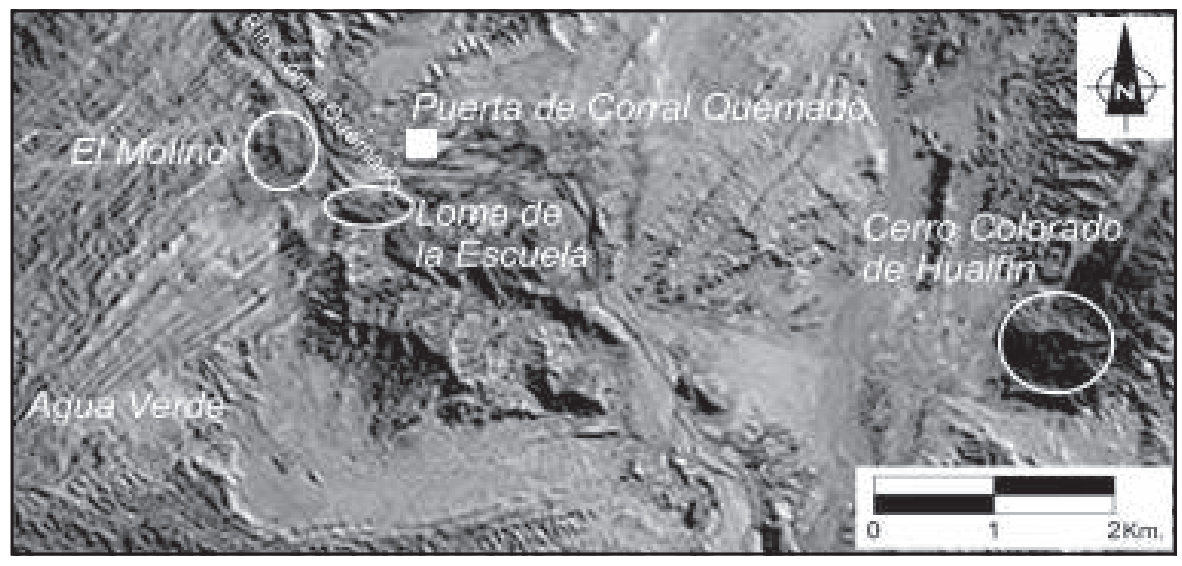

Figura 2: Detalle de las zonas en las que se localizaron las tumbas (Wolters 1924) 
en el campo, y otras se perdieron luego de haberse traído, pero disponemos del dibujo de su forma, que quedó registrado en el cuaderno. Otras piezas se hallan en proceso de búsqueda, de manera que en este trabajo tomamos en cuenta 6 piezas.

La adscripción de estas piezas al Período de Período de Desarrollos Regionales se realizó a través de su asociación en los entierros con cerámica fina Belén o Santa María y, para el caso de aquellas tumbas donde sólo se registraron piezas ordinarias, se las asoció cronológicamente de acuerdo a la similitud de la forma, los tipos de entierro y por su ubicación en los alrededores de El Molino, teniendo en cuenta que entre las 50 tumbas de la localidad cuyos ajuares forman parte de la colección, solamente dos tienen adscripción segura a otro período, en este caso al Formativo.

\section{Aspectos metodológicos}

La labor desarrollada con la cerámica ordinaria se limitó, en el presente trabajo, al registro y análisis de aquellos aspectos macroscópicos relacionados con la forma y el tamaño, junto con la observación de otros indicadores que podrían colaborar en las inferencias sobre la función, como es el caso del acabado de superficie, y la presencia y disposición de hollín.

Como los materiales de las unidades excavadas se hallaban en su totalidad en estado fragmentario, se buscó una forma de agrupar a los fragmentos que favoreciera la posibilidad de interpretarlos no como unidades aisladas, sino como posibles partes constitutivas de una pieza entera. De esta manera, y una vez realizado el remontaje en forma exhaustiva, se agruparon los tiestos remontados con los fragmentos sueltos que compartieran características comunes en una serie de atributos (sensu Rye 1981) seleccionados en torno a las unidades reconstruidas en mayor porcentaje. Así, se delimitaron 3 tipos de conjuntos (Figura 3) que contenían:

* Piezas parcialmente remontadas con formas diagnósticas indicadoras de bases, asas, cuellos y bordes, junto con porciones de cuerpo remontados y fragmentos sueltos,

* porciones de cuerpo remontados y fragmentos sueltos, y

* fragmentos agrupados, que compartían características similares en los atributos seleccionados.

Los principales atributos para definir los conjuntos fueron el aspecto general de la pasta, como el color y la textura; el acabado de superficie, el espesor y las marcas de confección o de uso. Asimismo, se tuvieron en cuenta la presencia de decoración, la curvatura de los fragmentos y la presencia y distribución de hollín. De esta manera, en la "Habitación 68" se construyeron 9 conjuntos ordinarios que agruparon al $40 \%$ de los fragmentos, en la 98 , el $64 \%$ de los fragmentos de la cerámica ordinaria quedó agrupada en 12 conjuntos, y en la 110, 4 conjuntos agrupan al $77 \%$ de los tiestos. Entre los fragmentos que no fueron agrupados, se seleccionaron para el análisis aquellos que incluían formas diagnósticas como cuellos, bordes, asas, bases o parte de ellos. Esta forma de agrupación de fragmentos produjo una mayor cantidad de información que si sólo se hubieran utilizado las piezas remontadas o los fragmentos por separado. Por ejemplo, tomando el arco de un conjunto de fragmentos que pertenecían al sector del cuerpo, se tuvo acceso a la medida del mínimo posible del diámetro máximo, en este caso de la pieza más grande de El Molino. 

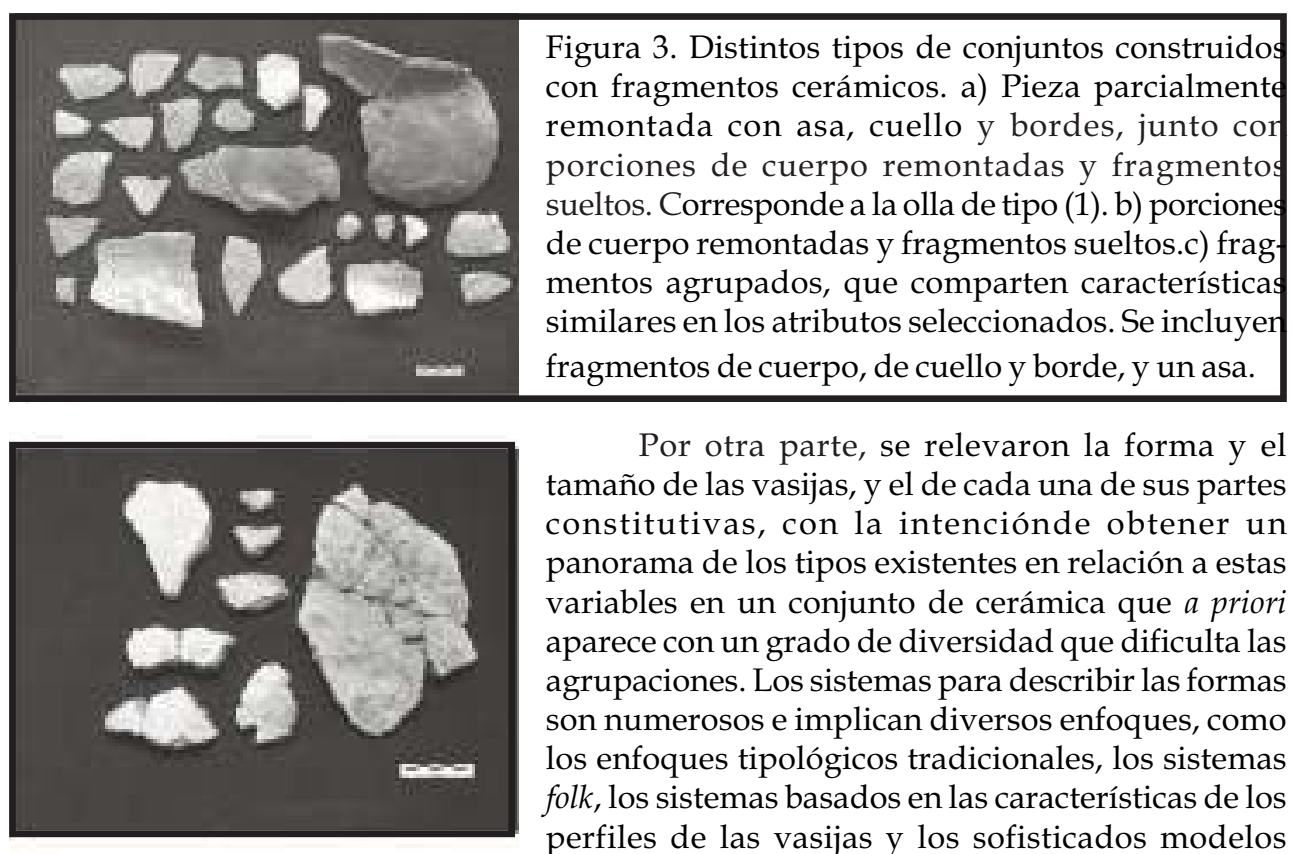

Por otra parte, se relevaron la forma y el tamaño de las vasijas, y el de cada una de sus partes constitutivas, con la intenciónde obtener un panorama de los tipos existentes en relación a estas variables en un conjunto de cerámica que a priori aparece con un grado de diversidad que dificulta las agrupaciones. Los sistemas para describir las formas son numerosos e implican diversos enfoques, como los enfoques tipológicos tradicionales, los sistemas folk, los sistemas basados en las características de los perfiles de las vasijas y los sofisticados modelos

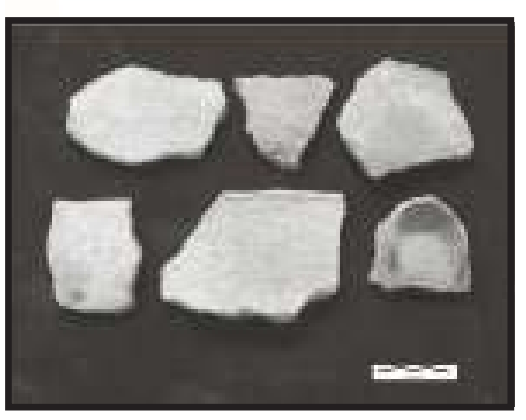
matemáticos (Shepard 1965, Rice 1987, Orton et al. 1997). Entre ellos, elegimos uno que combina el análisis de la forma con los índices de las dimensiones principales (altura, diámetro de abertura, diámetro mayor y altura del diámetro mayor en este caso) como lo es el sistema de clasificación de Balfet y colaboradoras (1992), cuya ventaja radica en que, si bien mantiene la terminología clásica de jarro, olla, plato, etc., cada categoría está claramente identificada a través de proporciones explícitas y por lo tanto no es de índole funcional.

Este sistema no se emplea en las primeras dos clases de piezas que se enumeran a continuación, para las cuales se ha elegido el nombre "tinaja ordinaria", dado que en la clasificación utilizada no se menciona ninguna categoría adecuada para estas formas.

En el caso de la existencia de piezas de forma y tamaño similar que difieren en otros aspectos, como por ejemplo tipo de acabado de superficie o decoración, se tomó en este trabajo la semejanza en las variables señaladas, aclarando las diferencias en otros atributos macroscópicos y si éstas podrían tener implicaciones en términos de uso.

De esta manera, se realizó una clasificación en tipos de formas y tamaños presentes tanto en los materiales procedentes del sitio como aquellos de la Colección, y se analizaron los indicadores enunciados por Rice (1987) para determinar las propiedades de las vasijas.

Por último, cuando fue posible se calculó el volumen de las piezas, con la intención de incorporar un indicador de la capacidad que permita vincular el tamaño, la forma y la 


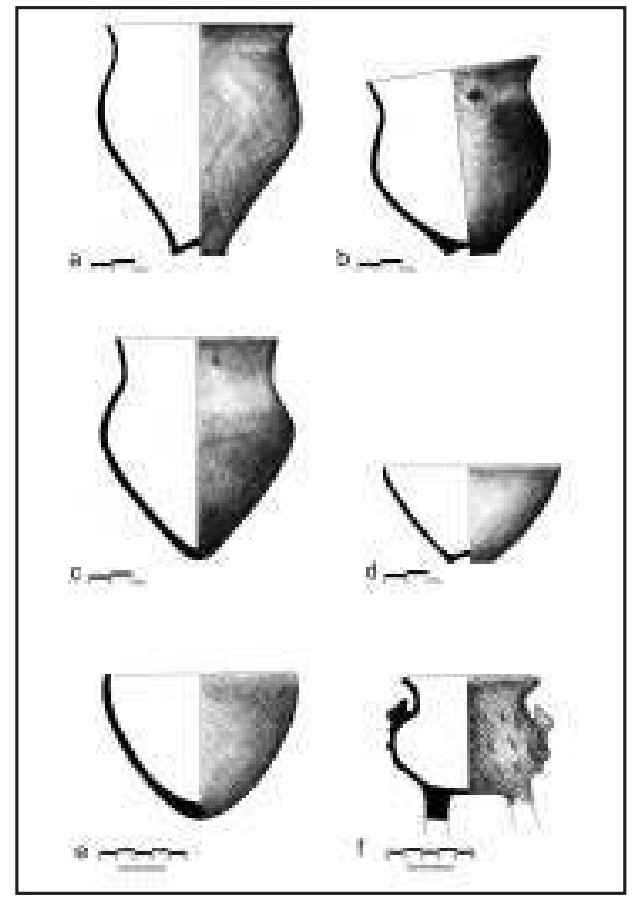

Figura 4. Piezas pertenecientes a la Colección Muñiz Barreto. a y b) Tinajas ordinarias de tipo (2). c) Tinaja ordinaria de tipo (1). d) Fuente. e) Vaso. f) Olla pequeña con patas.

\begin{tabular}{|c|c|c|c|c|c|c|c|c|c|}
\hline Piera & EP & AT & DA & DB-C & DC & DM & ADM & DB & $\begin{array}{l}\text { Vol. } \\
\text { (Itros) }\end{array}$ \\
\hline $\begin{array}{l}\text { 1. Tinaja } \\
\text { Ord. }\end{array}$ & 1,3 & 51 & 37 & 3,5 & 35,4 & 45 & 29 & Cono & 39,7 \\
\hline $\begin{array}{l}\text { 2. Tinaja } \\
\text { Ond. (A) }\end{array}$ & 1,4 & 55,5 & 44,8 & 5,2 & 41,5 & 48 & 31,7 & 13 & 50 \\
\hline $\begin{array}{l}\text { 2. Tinaja } \\
\text { Ond. (B) }\end{array}$ & 1,3 & $40,5-47$ & 41,7 & 7,5 & 37,4 & 42,5 & 23 & 11.7 & 47,2 \\
\hline 3. Fuen te & 1,3 & 23 & 41,5 & No tiene & No tione & 41,5 & 23 & 11,5 & 15,8 \\
\hline 4.Vaso & 0,8 & 8,5 & 11 & No tiene & No tiene & 11 & 8,5 & Cono & 0.5 \\
\hline 5,Olla peq & 0,6 & $6,5^{*}$ & 8 & 1,5 & 5,5 & 9.4 & 2.5 & Patas & 0,25 \\
\hline
\end{tabular}

Tabla 1

Medidas de las vasijas completas

EP: Espesor promedio de la pared. AT: Altura total. DA: Diámetro de abertura. DB-C: Distancia borde - inflexión del cuello. DC: Diámetro de la inflexión del cuello. DM: Diámetro máximo. ADM: Altura del diámetro máximo (Tomada desde la abertura de la vasija). DB: Diámetro de base.Vol.: Volumen. * Es la altura del cuerpo. Como las patas están incompletas la AT es imposible de calcular. Las vasijas no son simétricas. En general tienen diferencias de alturas. Aquí se promedian, excepto la 2B, cuya diferencia es muy grande. Todas las medidas están en centímetros. 
transportabilidad de las vasijas con la cantidad de contenido posible de ser introducido en ellas. Para ello se utilizó la técnica de Senior y Birnie (1995), que calcula el volumen a través de la medición, sobre una imagen de la vasija, de las alturas y radios de una serie de trapecios en los que se divide el perfil de la pieza, disminuyendo el error producido por la medición tradicional de cilindros propuesta por Nelson (1985). Por otra parte, con la intención de agrupar los volúmenes en función del uso, se estableció un límite arbitrario de capacidades pequeñas, medianas y grandes en vasijas de hasta un litro, de entre un litro y 20 litros, y de más de 20 litros. En el conjunto fragmentario, en el que no se puede estimar el volumen dado que desconocemos la forma de las vasijas completas, realizamos una estimación de la capacidad de las vasijas en función de la comparación de sus medidas con aquellas del conjunto de vasijas completas.

Los cuadernos de Wolters (Figura 5) señalan la existencia de 16 piezas del tamaño y forma de las tinajas ordinarias de tipo (1) y (2) en la zona, que fueron utilizadas como urnas.

\section{Las vasijas ordinarias de Puerta de Corral Quemado}

Colección Muñiz Barreto. Piezas de tumbas de zonas aledañas al sitio El Molino

1. Tinaja ordinaria (1). Vasija cerrada, de forma compuesta y perfil continuo. Tiene un cuello corto y evertido, su diámetro mayor se encuentra apenas sobre la mitad de la altura de la vasija, y su base es cónica, de manera que la vasija no puede sostenerse por sí misma cuando está boca arriba. Tiene $51 \mathrm{~cm}$ de altura y $37 \mathrm{~cm}$ de diámetro de abertura, con una constricción de $35 \mathrm{~cm}$. Cuenta también con 4 aplicaciones al pastillaje en forma de pequeños conos, que se localizan un par en cada lado opuesto, a la altura de la inflexión del cuello. Esta vasija está casi completamente impregnada de hollín, incluso en la base y en la superficie interna. La superficie externa es rugosa y la interna alisada (Figura $4 \mathrm{c}$ ). Las dimensiones de ésta y del resto de las piezas de la colección se consignan en la Tabla 1.

2. Tinaja ordinaria (2). Esta es la única categoría en la que se incluyeron dos vasijas. Varía con respecto a la anterior en que la base es de diámetro pequeño en relación a otras dimensiones, pero permite el apoyo de la vasija. Una de ellas, sin ningún elemento decorativo, tiene $55 \mathrm{~cm}$ de altura y $45 \mathrm{~cm}$ de diámetro de abertura, con una constricción de $41 \mathrm{~cm}$. La otra, con un par de aplicaciones al pastillaje en forma de granos de café en dos lados opuestos de la vasija, es un poco más pequeña, de $47 \mathrm{~cm}$ de altura mayor y $42 \mathrm{~cm}$ de diámetro de abertura. Ambas tienen hollín distribuido en forma heterogénea en los distintos sectores de las vasijas, y se repite la diferencia en los acabados de superficie interno y externo de la tinaja ordinaria de tipo (1) (Figura 4 a y b). de esas 16 solo 8 fueron traídas, mientras que las otras, que se hallaban muy fragmentadas, se dejaron en el campo. Hasta el momento se pudieron revisar 3 de esas 8,2 se hallan perdidas y las otras están en proceso de búsqueda. Es interesante señalar que los dibujos de las libretas no diferencian claramente cuál es el tipo de base que poseen estas piezas, dado que incluso la base cónica aparece dibujada con una base que le permite sostenerse sobre el suelo (Figura 4). Por lo tanto no podemos conocer la cantidad de piezas pertenecientes a cada clase $(1 \circ 2)$.

3. Fuente (Puco). Vasija abierta, cuyo diámetro de boca (superior a $40 \mathrm{~cm}$ ) tiene entre una vez y media y dos veces y media la dimensión de la altura (Balfet et al. 1992). Esta pieza tiene forma simple y perfil continuo, cuerpo en forma de cono truncado, una leve restricción en el borde, una base cóncavo-convexa y dos asas adheridas. (Figura $4 \mathrm{~d}$ ). Tiene una altura promedio 

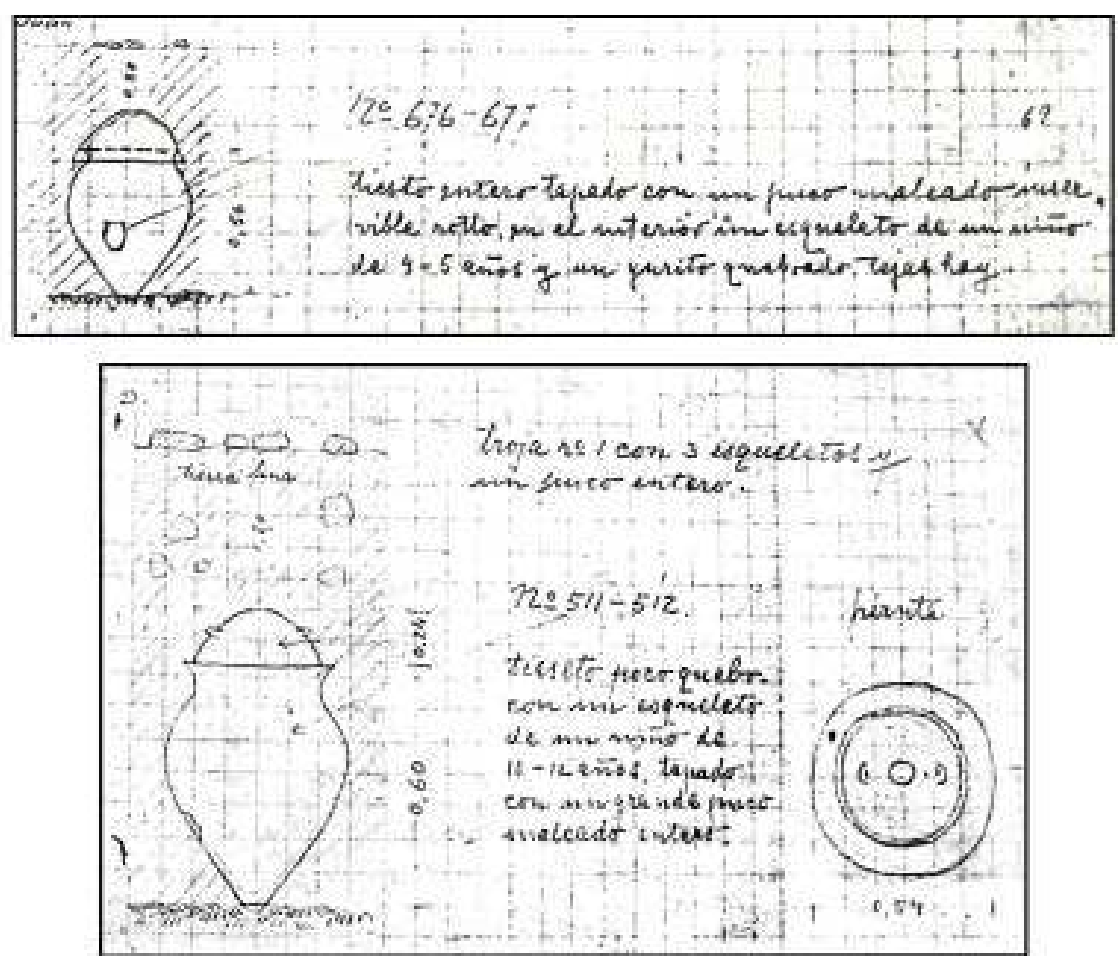

Figura 5. Dibujos del cuaderno de Wolters. a) Dibujo de la tinaja ordinaria de tipo (1) (con base cónica) b)Dibujo de una de las tinajas ordinarias de tipo (2) (con base cóncavoconvexa). El puco sobre la urna corresponde a la pieza descrita como fuente.

de $23 \mathrm{~cm}$, una abertura de $41,5 \mathrm{~cm}$ y un diámetro de base de $11 \mathrm{~cm}$. La superficie externa es rugosa, principalmente debido a las grandes inclusiones que sobresalen en la superficie, mientras que la superficie interna está alisada y tiene una serie de motivos grabados realizados de una manera poco cuidada. El hollín depositado en esta vasija está presente principalmente en la zona del borde del lado externo. La información de los cuadernos de Wolters (1924) indica que esta pieza estaba ubicada sobre una tinaja del tipo (1) o (2) a manera de tapa (Figura 4).

4. Vaso (Puco). Según Balfet y colaboradoras (1992), un vaso es una vasija abierta, cuyo diámetro de boca (de entre 6 y $12 \mathrm{~cm}$ ) es igual o inferior a una vez y media su altura. Esta pieza es simple, de perfil continuo, cuerpo cónico de paredes levemente redondeadas, y base cónica. Tiene una altura de $8,5 \mathrm{~cm}$ y un diámetro de abertura de $11 \mathrm{~cm}$. Ambas superficies están alisadas, aunque la interior en mayor grado, y en la superficie externa, con excepción de la zona de la base, presenta leves acumulaciones de hollín (Figura 4 e y 6 b).

5. Olla pequeña con patas. Balfet et al. (1992) definen como "olla" a aquellas vasijas cerradas cuyo diámetro mínimo es igual o superior a un tercio del diámetro máximo. Además esta pequeña pieza es compuesta y de perfil continuo. Presenta cuello corto evertido, cuerpo globular y tres patas. Tiene $8 \mathrm{~cm}$ de diámetro de abertura y $6,5 \mathrm{~cm}$ de altura. Las patas están incompletas, pero se puede suponer por su diámetro que la pieza entera no tenía más de 10 


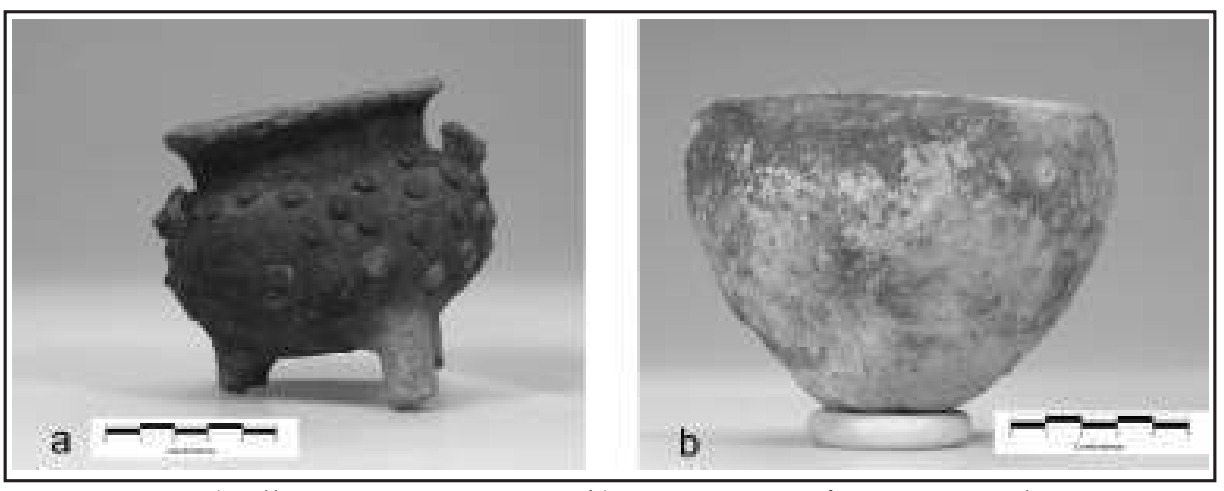

Figura 6. a) Olla pequeña con patas. b) Vaso. Fotografías: María Delia Arena.

cm de altura. La vasija se encuentra completamente impregnada de hollín, en menor medida en las patas que en el cuerpo, y tiene como elementos decorativos dos asas modeladas con cabezas zoomorfas y pequeños círculos aplicados al pastillaje que cubren casi todo el cuerpo. La superficie interna está bien alisada (Figura 4 f y 6 a).

Piezas de las estructuras excavadas en El Molino

1. Ollas (1). Vasijas cerradas, de forma compuesta y perfil continuo. Poseen un cuello corto evertido y forma globular. La que se encontraba en la Habitación 68 (Olla 1a) tiene 22 $\mathrm{cm}$ de diámetro de abertura, y un ancho máximo de alrededor de $27 \mathrm{~cm}$. La otra vasija (Olla 1b), procedente de la Habitación 98, tiene aproximadamente $21 \mathrm{~cm}$ de diámetro de abertura y un diámetro máximo de cerca de $26 \mathrm{~cm}$. Las dos tienen un acabado de superficie interno bien alisado, mientras que la superficie externa es más áspera. La primera vasija (Figura 7 a y $9 \mathrm{~b}$ ) presenta grupos de incisiones en distintas direcciones, y la otra tiene un alisamiento que ocultó las huellas del levantado de la pieza pero dejó la superficie rugosa. Además posee una serie de aplicaciones al pastillaje de forma circular dispuestas regularmente en la vasija.

\begin{tabular}{|c|c|c|c|c|c|c|c|c|c|}
\hline Рieza & $\begin{array}{c}\text { Habita- } \\
\text { ciön. }\end{array}$ & EP & AMP & DA & DB-C & DC & DM & DMP & ADM \\
\hline 1a & 68 & 0,8 & 18,5 & 22 & 2,5 & 19,5 & 27 & No over. & 13,5 \\
\hline Ib & 98 & 0,8 & 16 & -20 & 2,5 & 18 & 26,5 & No over. & 13 \\
\hline 2 & 68 & 1,1 & 17,5 & 34 & 5 & 19,5 & lndet. & 65 & lndet. \\
\hline 7 & 110 & 0,9 & 13,5 & 38 & No tiene & No tiene & Abertura & No & Abertura \\
\hline
\end{tabular}

Tabla 2

Medidas de las vasijas fragmentadas.EP: Espesor promedio de la pared. AMP: Altura máxima parcial. DA: Diámetro de abertura. DB-C: Distancia borde - inflexión del cuello. DC: Diámetro de la inflexión del cuello. DM: Diámetro máximo. Indet.: No se puede determinar. DMP: Diámetro máximo parcial (mínimo del diámetro máximo). ADM: Altura del diámetro máximo (Tomada desde la abertura de la vasija). No corr. : No corresponde, la vasija está incompleta. $\neg$ : Medidas aproximadas, dado el estado fragmentario del conjunto.Todas las medidas están en centímetros. 
El hollín se halla presente en las dos piezas, en la primera mediante una cobertura heterogénea que va desde sectores limpios a sectores muy impregnados, y la segunda se encuentra completamente cubierta en ambas caras. Las medidas de estas y el resto de vasijas de este grupo se detallan en la tabla 2.

2. Olla (2). Vasija cerrada, compuesta y continua. Esta pieza, procedente de la Habitación 68 , es la de mayores dimensiones del universo analizado. Tiene un diámetro de abertura de $34 \mathrm{~cm}$ con una constricción de $31 \mathrm{~cm}$. No se ha podido reconstruir la vasija completa, pero por la similaridad de atributos se establecieron asociaciones con otros fragmentos que llegan a tener $65 \mathrm{~cm}$ de diámetro, medido a través de su cuerda, indicando un mínimo posible para la medida de diámetro máximo. Esta olla está libre de depósitos de hollín (Figura 7 b).

3. Cuenco grande (Puco). Balfet et al. (1992) definen al cuenco grande de la misma manera que la fuente, pero su diámetro de boca tiene entre 19 y $40 \mathrm{~cm}$. La pieza está incompleta, pero se puede suponer que la vasija entera era simple y tenía entre 15 y $20 \mathrm{~cm}$ de altura, de manera que con sus $38 \mathrm{~cm}$ de abertura pertenecería a esta categoría. Esta pieza, al igual que el puco de colección, tiene incisiones en el interior de la vasija, que en este caso forman un reticulado, y en su contexto de uso final funcionó como tapa de la urna citada anteriormente (Figura 9 a).

4. Bases en pedestal. Las bases en pedestal son un grupo de 5 bases, posiblemente 7 si se tienen en cuenta dos que se encuentran muy erosionadas, distribuidas en las tres habitaciones. Son biconvexas y tienen un punto de tangencia vertical (sensu Shepard 1965) que produce un contorno convexo en sus perfiles. El diámetro de la superficie de apoyo varía entre los 10 y 14 $\mathrm{cm}$, y el diámetro de inflexión entre los 9 y $12 \mathrm{~cm}$. Una característica destacable es que la altura del punto tangencial en todas ellas está cerca de los 2,5 cm (Figura 8).

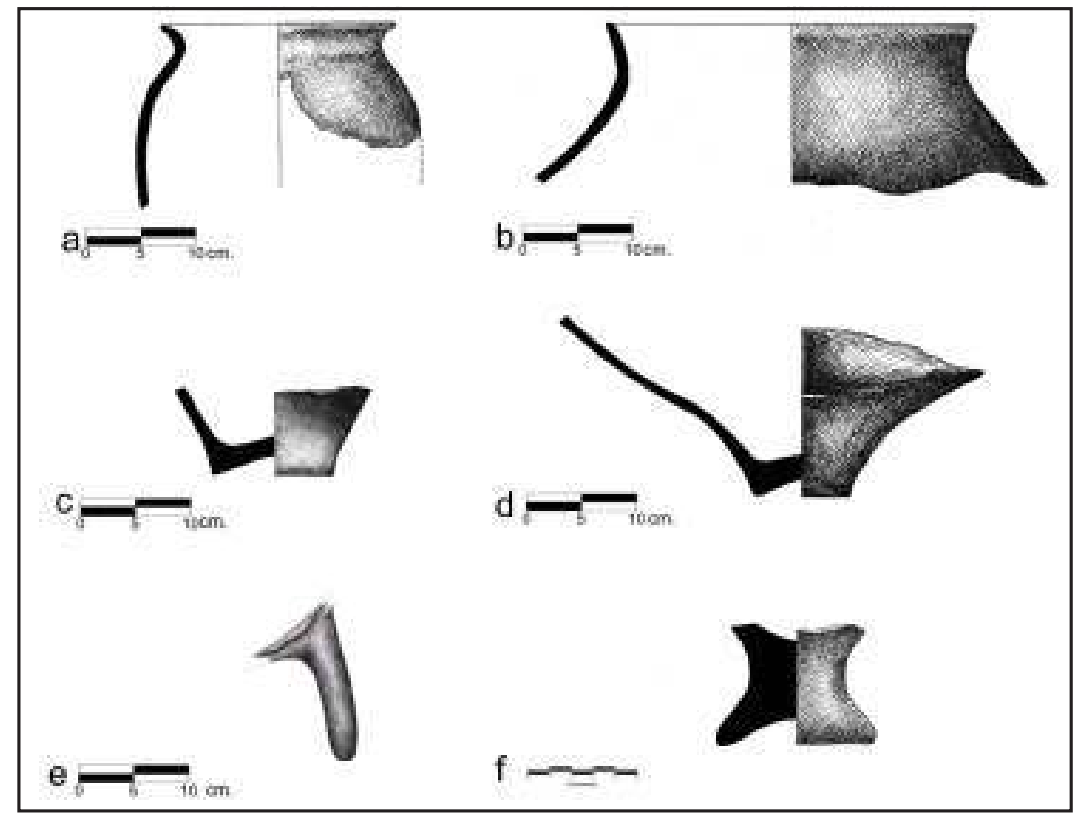

Figura 7. Piezas procedentes de las estructuras excavadas en El Molino. a) Olla de tipo (1). b) Olla de tipo (2). c) Bases cóncavo-convexas. d) Base trípode. e) Base en pie. 


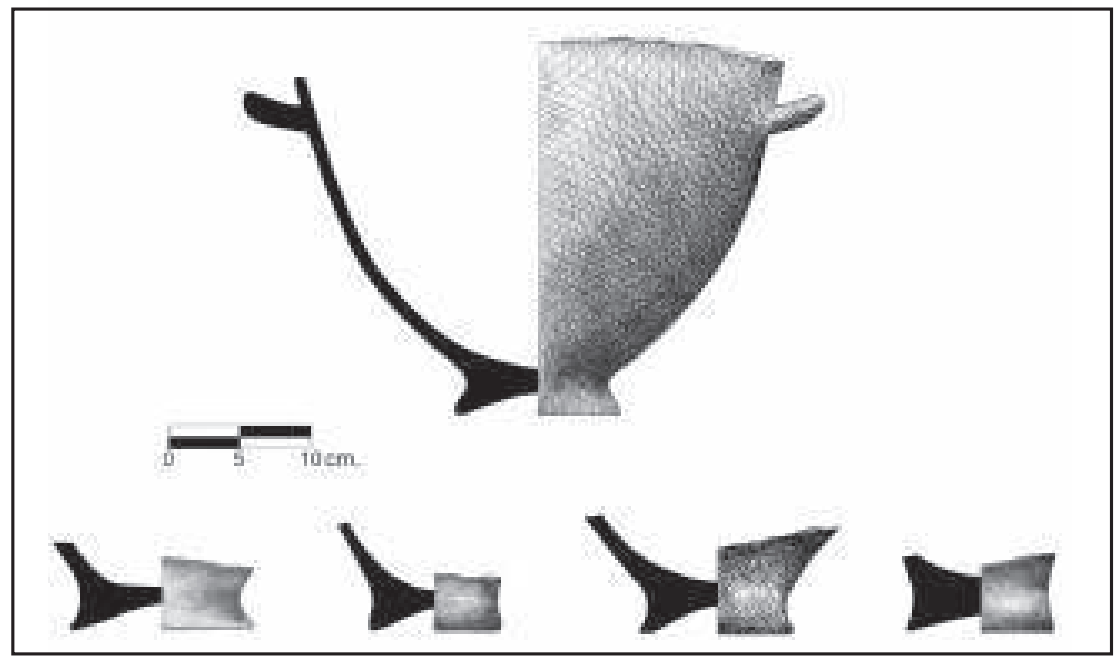

Figura 8. Bases en pedestal.

No se ha podido determinar la forma de la vasija que portaba este tipo de base. Hay dos casos que conservan partes importantes de las paredes, en los dos lo hacen con ángulo distinto, ninguna de las dos posee el punto de inflexión que permitiría establecer al menos el diámetro máximo de la vasija. En una de ellas se destaca la presencia de un elemento para asir.

Las bases que forman este grupo tienen distintos niveles de depósitos de hollín, algunas están completamente impregnados y otras presentan sus superficies blanquecinas, posiblemente debido a su contacto directo con el fuego. Las medidas de las bases se detallan en la Tabla 3.

5. Base en pie. Se trata de una base biconvexa de la Habitación 98 con un perfil de contorno convexo, al igual que la base en pedestal. La diferencia entre ambos tipos radica en que la superficie de apoyo de la base en pie es pequeña, de $7 \mathrm{~cm}$, y cambia la altura del punto tangencial vertical, que en este caso es de 3,3 cm (Figura $7 \mathrm{f}$ ). De esta manera, en términos proporcionales, las bases en pedestal son más anchas que la base en pie.

6. Bases cóncavo-convexas. Se hallaron dos bases de este tipo, de 12 y 9,4 $\mathrm{cm}$ de diámetro en la superficie de apoyo, ubicadas en las habitaciones 68 y 110 respectivamente (Figura 7 c y d). La segunda está completamente impregnada de hollín y, por lo informado en sus etiquetas, era el contenedor del esqueleto de un niño de aproximadamente 1 año de edad (García Mancuso e Iucci 2008).

7. Base con patas, posiblemente trípode. Este tipo de base se determinó a partir de dos fragmentos que corresponden a dos posibles patas de $9,5 \mathrm{~cm}$ de alto, $5 \mathrm{~cm}$ de ancho mayor promedio y $3,5 \mathrm{~cm}$ de ancho menor, de manera que la sección horizontal forma un óvalo. Una de las patas incluye una pequeña porción del fondo de la pieza, que indica que la pata la levantaba a unos $8 \mathrm{~cm}$ sobre el suelo (Figura 7 e). La hipótesis sobre su ubicación en la vasija se realizó a partir de la comparación con una pieza de colección. 


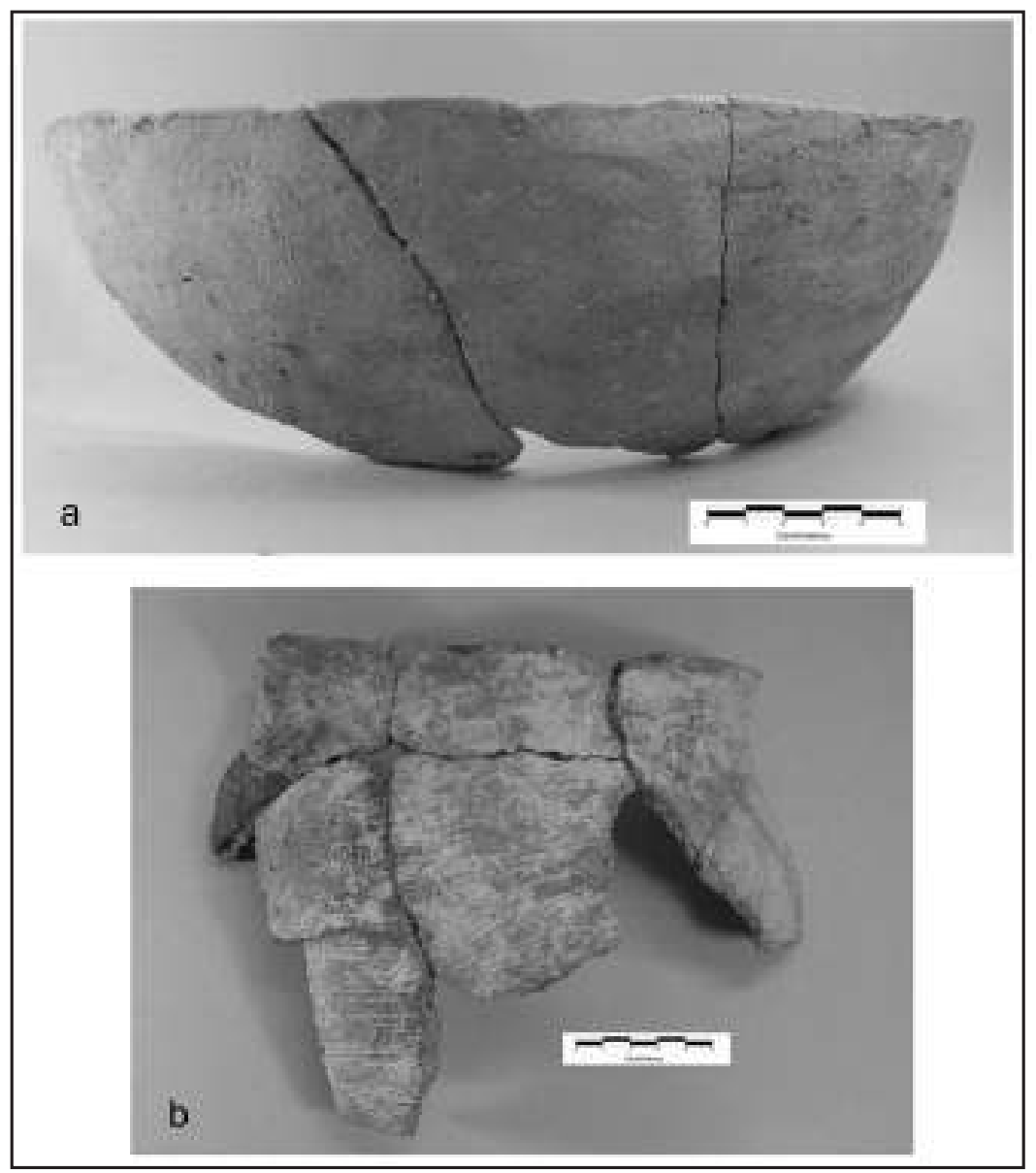

Figura 9. a) Cuenco grande. a) Olla de tipo (1).

\section{Función de las vasijas inferida en base a la forma y el tamaño}

Una vez realizada la descripción de las formas existentes en el universo estudiado, y teniendo en cuenta las variables de la forma de las vasijas que intervienen en la función enumeradas por Rice (1987), revisaremos las posibilidades funcionales de las piezas examinadas. Las tablas 4 y 5 sintetizan lo expuesto.

En primer lugar observamos una variedad de tamaños que permiten pensar en funciones diversas con capacidades para distintas cantidades de usuarios. Los recipientes de menor tamaño, el vaso y la olla pequeña, tienen capacidades para poca cantidad de contenido, en este caso menor a 1 litro, adecuada posiblemente para porciones individuales. La inflexión de la olla pequeña cerca de la boca permite manipular con mayor facilidad cotenidos líquidos que sólidos. Las ollas (1) son contenedores de tamaño mediano, con una abertura suficiente como para introducir elementos para procesar el contenido. Entre las piezas más grandes, la vasija con base en pedestal reconstruida en mayor porcentaje puede haber tenido un tamaño 
grande, pero no tanto como el de las tinajas ordinarias del contexto funerario. Los tamaños de estas últimas son muy grandes como para afirmar que fueron usadas en la elaboración de comidas cotidianas para una familia nuclear, probablemente tuvieron números grandes de usuarios.

Por último, las dimensiones de la olla (2) exceden el promedio de $45 \mathrm{~cm}$ de diámetro máximo de las tinajas ordinarias, tiene una abertura de boca de la mitad del diámetro máximo inferido y un cuello con una constricción importante. La relación diámetro de abertura diámetro máximo no es adecuada para la introducción de una mano o algún utensilio, de manera que se adecua mejor a la función de almacenamiento y no tanto a la de procesamiento. La ausencia de depósitos de hollín en sus superficies apoya la idea de que no se usó para procesar su contenido sobre el fuego.

Las piezas del universo analizado, con las excepciones de la olla pequeña y, posiblemente, la portadora de la base trípode, son inestables en distinto grado. Por ejemplo, las tinajas ordinarias de tipo (2) son altas y de base estrecha, se sostienen por sí mismas pero pueden ser inclinados fácilmente sin necesidad de levantar la pieza cuando está llena, lo que constituiría una ventaja para volcar o pasar el contenido a otro recipiente en el caso de que fuera líquido o, si hubiese sido sólido, habría sido suficiente arrastrar el contenido con la mano o algún otro elemento mientras la vasija estaba inclinada. La tinaja ordinaria de tipo (1), en cambio, no se sostiene por sí sola, es pesada y grande, de manera que es difícil de soportar colgando. Por otra parte, debido a la presencia de abundante hollín en sus superficies, sabemos que fue colocada sobre el fuego, de manera que fue necesario utilizar algún elemento de sostén que no dejó huellas, al menos en el nivel macroscópico de observación.

Las bases cóncavo-convexas también son angostas en relación al tamaño de las vasijas. En el caso de la que funcionó como urna, dado que la pared se ensancha considerablemente, la pieza permanece en equilibrio cuando se encuentra en pie. Estas bases en general muestran huellas de haber sido expuestas al fuego. Pueden estar o bien impregnadas de hollín o bien mostrarse con coloraciones claras y recocidas, como producto del contacto directo con el fuego y no con el humo que éste produce (Zagorodny 1996). Así, el reborde en la superficie de apoyo de las bases en pedestal les confiere, en comparación con las cóncavo-convexas, un mayor grado de estabilidad cuando se encuentran apoyadas, sobre todo en superficies

\begin{tabular}{|c|c|c|c|c|c|c|c|c|}
\hline Givipo & Hibit. & Pieza & DSA & DIB & $\mathrm{AIB}$ & ECB & $\mathrm{ACB}$ & EPCI \\
\hline \multirow{5}{*}{ 4. pedestal } & 68 & 1 & 11,7 & 10.9 & 2 & 2.2 & 2 & 1 \\
\hline & 68 & 2 & 10.1 & 9.8 & 2.5 & 1.3 & 1,75 & 0.85 \\
\hline & 68 & 3 & 11,3 & 10.2 & 2,6 & 2.9 & 1,3 & Indet. \\
\hline & 98 & 4 & 13 & 12,2 & 2.5 & 2.1 & 1,1 & 1.4 \\
\hline & 110 & 5 & 14 & 12 & 2,5 & 1.25 & 2 & 1,35 \\
\hline 5 & 98 & $\mathrm{Pic}$ & 7 & 4,5 & 3,3 & 3,5 & 1,2 & bdet. \\
\hline \multirow{2}{*}{ 6. $\propto \mathrm{C}$. } & 98 & $\mathrm{CCl}$ & 14 & No tiene & No tiane & $-1,85$ & -2 & bdet. \\
\hline & 110 & $\mathrm{CC} 2$ & 9.4 & No tiens & Noticne & 2.2 & 1.8 & 1.4 \\
\hline
\end{tabular}

Tabla 3

Medidas de las bases (grupo de vasijas fragmentadas) DSA: Diámetro de la superficie de apoyo. DIB: Diámetro de la inflexión de la base. AIB: Altura de la inflexión de la base. ECB: Espesor del centro de la base. ACB: Altura del centro de la base. EPCI: Espesor pared cuerpo inferior. CC: Cóncavo-convexa. $\neg$ : Medidas aproximadas, dado el estado fragmentario del conjunto. Todas las medidas están en centímetros 


\begin{tabular}{|c|c|c|c|c|c|c|c|}
\hline \multirow{2}{*}{$\begin{array}{c}\text { Variables } \\
\text { posibles de ser } \\
\text { manipuladas }\end{array}$} & $\begin{array}{c}\text { Tinaja } \\
\text { Ordinari a ( } 1)\end{array}$ & $\begin{array}{c}\text { Tinaja } \\
\text { ordinanial (2) }\end{array}$ & $\begin{array}{l}\text { Fuerite? } \\
\text { Cuanco } \\
\text { grande }\end{array}$ & Vasio & Olla pequeña & $\mathrm{OHla}_{2}(1)$ & Olla (2) \\
\hline & & & & & & & \\
\hline Gimnde & $x$ & $\mathrm{x}$ & & & & & $x$ \\
\hline Mediana & & & $x$ & & & $x$ & \\
\hline Peguefís & & & & $x$ & $x$ & & \\
\hline $\begin{array}{l}\text { Centro de } \\
\text { Gravodad Bigio }\end{array}$ & & & $\mathrm{x}$ & & $x$ & $x$ & Inde. \\
\hline \multicolumn{8}{|l|}{$\begin{array}{l}\text { R. Base-altura } \\
\text { estable }\end{array}$} \\
\hline $\begin{array}{l}\text { Orificio } \\
\text { srande }\end{array}$ & $\mathrm{x}$ & $\mathrm{x}$ & $\mathrm{x}$ & $x$ & & $\mathrm{x}$ & $x$ \\
\hline Mltura total* & $\mathbf{x}$ & $\mathrm{x}$ & $\mathbf{x}$ & $\mathrm{x}$ & $x$ & $\mathbf{x}$ & Indat. \\
\hline $\begin{array}{l}\text { Agarre - } \\
\text { Exterior } \\
\text { desparcio }\end{array}$ & $\mathrm{x}$ & $\mathrm{x}$ & $\mathrm{x}$ & & $x$ & $x$ & $x$ \\
\hline $\begin{array}{l}\text { Elementos } \\
\text { Dana asir }\end{array}$ & & & $\mathrm{x}$ & & $x$ & & \\
\hline Pared delgada & $\mathrm{x}$ & $\mathrm{x}$ & $\mathrm{x}$ & $x$ & $x$ & $x$ & $x$ \\
\hline $\begin{array}{l}\text { Contceno } \\
\text { simpleo } \\
\text { inflexionado }\end{array}$ & $\mathrm{x}$ & $\mathrm{x}$ & $\mathrm{x}$ & $x$ & $x$ & $\mathrm{x}$ & $x$ \\
\hline $\begin{array}{l}\text { Posibelidad de } \\
\text { ciorreve }\end{array}$ & $x$ & $\mathrm{x}$ & & & & & $x$ \\
\hline Pared scruesi & & & & & & & \\
\hline $\begin{array}{l}\text { Parod interna } \\
\text { alisada }\end{array}$ & $\mathbf{x}$ & $\mathrm{x}$ & & $\mathrm{x}$ & $\mathrm{x}$ & $\mathbf{x}$ & $\mathbf{x}$ \\
\hline
\end{tabular}

Tabla 4

Variables que definen propiedades de las vasijas. * Altura total que permite alcanzar el fondo de la vasija. ** Posibilidad de cierre inferida por hallarse en contexto arqueológico cerrado con laja o tapa.

irregulares como lo son las brasas. Pero a la vez, por la estrechez y altura de la base, que eleva el centro de gravedad, es posible que haya podido ser volcada fácilmente.

Las vasijas con patas, que también tienen este tipo de coloración blanquecina, podían ser colocadas sobre el fuego con un alto grado de estabilidad, y por el otro lado, al levantar el fondo de la vasija, no se ponía el contenido en contacto directo con el fuego, evitando así que se queme.

La base en pie probablemente constituía una superficie de apoyo que le daba inestabilidad a la vasija que soportaba, y, como las únicas huellas de exposición al fuego de la vasija son 


\begin{tabular}{|c|c|c|c|c|c|c|c|}
\hline Propiedades & $\begin{array}{c}\text { Tin ąia } \\
\text { Ordinaria } \\
\text { (1) }\end{array}$ & 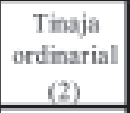 & $\begin{array}{l}\text { Fumbef } \\
\text { Cuenco } \\
\text { grande } \\
\end{array}$ & Vaso & $\begin{array}{c}\text { Olla } \\
\text { pequata }\end{array}$ & Olla (1) & Olla (2) \\
\hline Capacidad & $\mathrm{XXX}$ & $x \times x$ & $\mathrm{xx}$ & $\mathrm{x}$ & $\mathrm{x}$ & $\mathrm{xx}$ & $\mathrm{xxX}$ \\
\hline Estable & $\mathrm{x}$ & $\mathrm{x}$ & $\mathrm{xx}$ & $\mathrm{x}$ & $\mathrm{xxx}$ & $\mathrm{xx}$ & bolet \\
\hline Accesible & $\mathrm{xX}$ & $x x$ & $\mathrm{XXX}$ & $\mathrm{xxX}$ & $\mathrm{xx}$ & $\mathrm{XXX}$ & $\mathrm{XxX}$ \\
\hline Transportable & $\mathrm{X}$ & $\mathrm{x}$ & $\mathrm{xx}$ & $\mathrm{xxx}$ & $\mathrm{xxx}$ & $\mathrm{xxx}$ & $\mathrm{xxx}$ \\
\hline $\begin{array}{l}\text { Adecuación a la } \\
\text { exposición al } \\
\text { calor }\end{array}$ & $\mathrm{xxx}$ & $\mathrm{xxx}$ & $\mathrm{xxx}$ & $\mathrm{xx}$ & $\mathrm{xxx}$ & $\mathrm{xxx}$ & $\mathrm{xxx}$ \\
\hline Almacxnaministo & $x x$ & $\mathrm{xx}$ & $x$ & $x$ & $\mathrm{x}$ & $x$ & $\mathrm{xxx}$ \\
\hline Procesamienso & $\mathrm{xx}$ & $x x$ & $x$ & $\mathrm{xx}$ & $\mathrm{xx}$ & $\mathrm{xxx}$ & $\mathrm{xxx}$ \\
\hline
\end{tabular}

Tabla 5

Propiedades funcionales de las vasijas De $\mathrm{x}$ a xxx: de menor a mayor posibilidad de desempeñar con eficiencia la propiedad. En el caso de capacidad, $x x x=$ grande, $x x=$ mediana $\mathrm{y} \mathrm{x}=$ pequeña.

sobre los bordes y las fracturas, se interpreta que su exposición al fuego fue posterior a su ruptura y no durante su uso primario.

Con respecto a la accesibilidad, las vasijas del conjunto son abiertas y cerradas, pero las cerradas no lo son suficientemente como para inferir una funcionalidad ligada exclusivamente a la contención y servicio de líquidos. El cerramiento de las vasijas es en general una leve constricción que determina un cuello corto y evertido, del que puede inferirse que o bien haya sido utilizado para atar algún tipo de cuerda para la sujeción del recipiente, muy improbable en el caso de las vasijas más grandes, o bien que este cerramiento haya permitido la introducción de elementos para procesar pero disminuido las posibilidades de derramar los contenidos, así como contribuir al mantenimiento del calor.

La función de transporte está bien representada en la fuente y el cuenco grande, cuyas aperturas las hace ideales tanto para el servicio de alimentos o su transporte en cortas distancias, como para la presentación o traslado de otros elementos no comestibles. La presencia de incisiones a modo de decoración en el interior de estas piezas, que es la parte más visible cuando está en uso, refuerza la idea de que podrían haber sido utilizadas para presentar contenidos. Pero esta función de servicio no excluye que hayan tenido otras posibilidades funcionales, tales como calentar o mantener calientes distintas sustancias sobre brasas, lo cual se desprende de las leves acumulaciones de hollín en algunos sectores de las piezas. Para trasladar líquidos este tipo de piezas tenían la desventaja de ser demasiado abiertas y permitir el derrame de sus contenidos fácilmente.

El vaso posibilita el servicio y quizás el traspaso de contenidos $y$, si bien no posee ningún elemento para asir que aleje la mano del calor, posee depósitos de hollín que indican que este recipiente tuvo algún tipo de contacto con el fuego.

Las tinajas ordinarias, al contrario que la fuente, son grandes, pesadas y no llevan ningún elemento para asir, por lo tanto eran difíciles de ser trasladadas a grandes distancias. Las rugosidades en la cara externa facilitaban el sostén o su capacidad para ser transportadas en cortas distancias, sobre todo para acomodarlas en el lugar del procesado de los contenidos. 
A pesar de que el grosor de las vasijas analizadas presenta variaciones graduales en función del sector de la pieza que se contempla, pudiendo ser más anchos, por ejemplo, en las paredes que se ubican cerca de las bases, sobre todo en el caso de las piezas más grandes, no se registraron cambios bruscos de espesor, mientras que las marcas de los rollos de arcilla y sus uniones están ocultas. Esta uniformidad de grosores de las paredes le confiere a la pieza mayor resistencia al stress térmico, y ésta a la vez se incrementa con la inexistencia en el conjunto analizado de paredes con ángulos agudos.

Otra característica recurrente registrada en el conjunto se relaciona con la capacidad del acabado de superficie para contribuir con la eficiencia funcional de las vasijas. Con excepción del cuenco y la fuente mencionados arriba, las vasijas analizadas presentan en las superficies internas un alisado que disminuye la porosidad y oculta las inclusiones de las pastas y algunas huellas de manufactura que sí se conservan en las superficies externas, donde además es común la presencia de elementos decorativos tales como incisiones y aplicaciones al pastillaje. Esta diferencia entre ambas paredes responde probablemente a razones funcionales. Por un lado, la superficie interna alisada protege a los contenidos de la humedad externa y disminuye la penetración del contenido en las paredes. Por otro lado, el exterior rugoso y más poroso incide en las propiedades térmicas de las vasijas, sobre todo en este conjunto donde la mayoría tiene huellas de haber sido sometida al fuego: las rugosidades generan una superficie mayor para absorber calor y evaporar líquidos, además de incrementar la resistencia al stress térmico. Por otro lado, les confiere a las vasijas, con respecto a la función de transporte, mayor facilidad para sujetarlas.

\section{Reflexiones finales. Forma, tamaño, función y contexto de las vasijas ordinarias de Puerta de Corral Quemado}

Uno de los primeros aspectos a señalar es el referente a la regularidad observada en la forma de algunas de las piezas estudiadas. A partir de la existencia de 7 bases semejantes en el contexto doméstico por un lado, y 16 tinajas ordinarias en el contexto funerario relevadas por Wolters, por el otro, podemos afirmar que existe una recurrencia de formas de algunos tipos de piezas dentro del conjunto examinado que indican que los ceramistas que las confeccionaban tenían una planificación previa de la pieza que querían obtener, además de los conocimientos técnicos para elaborarlas. De esta manera, producían piezas que cumplían con algunos requerimientos funcionales, tales como su adecuación a la cantidad de usuarios, su facilidad para ser volcadas y manipuladas o su resistencia al stress térmico.

Estas regularidades están asimismo relacionadas con ciertas funciones inferidas y usos efectivos que pudieron haber tenido estas piezas. Como mencionamos anteriormente, las piezas con las que contamos provienen, por un lado, de un contexto funerario en el que fueron usadas directamente como urnas o como ajuar funerario y, por el otro, de un poblado arqueológico con características defensivas y estructuras arquitectónicas de distinto tipo, en las cuales encontramos piezas que probablemente estaban relacionadas con el ámbito doméstico, aunque se incluye también un entierro de subadulto en uno de los recintos, y una vasija fina y completa debajo del piso de otro.

Con la excepción de una tinaja ordinaria que no contenía restos humanos, todas las piezas de este tipo que se registraron en el campo fueron usadas como contenedores funerarios, específicamente de subadultos. Si bien no todas ellas, en su función de urnas, tenían tapa, se 
registran 11 casos en que los pucos ordinarios fueron usados como tapas de las tinajas ordinarias en el contexto funerario. Las tres tinajas que se pudieron examinar hasta el momento tenían depósitos de hollín en las superficies interna y externa, lo cual indica que fueron efectivamente utilizadas antes de su uso como contenedor funerario.

Entre las bases registradas en El Molino, dos son cóncavo-convexas, es decir, su forma coincide con la forma de al menos dos de las tinajas halladas en la colección. Una presenta los mismos atributos de pasta que la olla más grande, así como la ausencia de depósitos de hollín, a la que se le atribuye la función de almacenamiento. La otra base cóncavo-convexa funcionó como urna funeraria, $y$, al igual que las tinajas ordinarias de la colección, se encuentra completamente cubierta de hollín.

Las vasijas funerarias de la colección no presentan bases en pedestal, en cambio, en sólo tres estructuras de El Molino se hallaron siete. Esto constituye una diferencia significativa en cuanto al uso de vasijas particulares en cada ámbito, el doméstico y el funerario. En las tumbas tampoco se hallaron vasijas de tamaño mediano, como las ollas de tipo (1) descritas anteriormente. Y la única vasija del sitio que tiene características morfológicas semejantes a las tinajas ordinarias utilizadas como urnas, fue efectivamente usada como contenedor funerario.

Una explicación posible de las diferencias observadas en ambos grupos se puede vincular con los resultados de un trabajo de carácter etnoarqueológico sobre el uso de vasijas realizado en la puna de Jujuy. Menacho (2001) observa que las diferencias de tamaño en las piezas utilizadas para la cocción de alimentos están ligadas a las cantidades de alimentos preparados en distintos contextos de uso, doméstico o ritual, y no a los tamaños de las unidades domésticas, donde se prefiere variar la cantidad de piezas pequeñas utilizadas y no su tamaño. Esto respondería al tamaño de las estructuras existentes para la cocción en el contexto doméstico, que sirven como reparo del viento, frío y lluvia; y al uso de combustible que abunda localmente y es fácil de conseguir, a diferencia de la leña necesaria para cocinar en vasijas más grandes y durante tiempos prolongados.

Por lo tanto, si bien a través de lo observado en ambos conjuntos pueden cubrirse una amplia variedad de funciones posibles determinadas por las formas de las vasijas, las observaciones realizadas sugieren que los conjuntos pertenecientes a cada contexto son diferentes, cumpliendo posiblemente con funciones relacionadas con cada esfera. Las ollas (1) y las vasijas en pedestal podrían haber intervenido en la elaboración diaria de alimentos, mientras las tinajas ordinarias eran confeccionadas para eventos que convocaran a un número mayor de personas, como por ejemplo, un ritual funerario.

Un último aspecto que nos queda por considerar es el referente al traslado de agua y líquidos en general. Como dijimos, el sitio El Molino se encuentra sobre una lomada de 70 metros de altura, a donde habría que haber trasladado el agua desde el río. Si bien Skibo (1992) ha observado que muchas veces se usan las mismas vasijas de cocina para acarrear agua, las vasijas que hemos analizado cuentan con pocos y pequeños elementos para asir con eficiencia a las piezas llenas que deban trasladarse a través de estas distancias. No obstante, las vasijas ordinarias están acompañadas también por piezas "finas", en las que se incluyen tinajas y pucos. Wynveldt (2007) ha sugerido que las tinajas Belén halladas en el contexto doméstico del sitio Loma de los Antiguos de Azampay estaban destinadas 
posiblemente a la contención de agua. Esto se deriva de las observaciones realizadas sobre el tipo de asas remachadas, la delgadez de las paredes y el baño de arcilla que, al recubrir la superficie, reduce la porosidad de las piezas, disminuyendo el grado de evaporación de los contenidos.

A lo largo de este trabajo se han revisado una serie de características de las vasijas ordinarias en cuanto a la forma y tamaño, sugiriéndose a partir de ellos distintas posibles funciones y usos, que no deben ser consideradas como concluyentes, sino como hipótesis que serán contrastadas con nuevos análisis, de manera de generar una aproximación integral a la utilización de vasijas en el pasado.

\section{Agradecimientos}

A los Dres. Bárbara Balesta y Federico Wynveldt, y a la Lic. Nora Zagorodny por las sugerencias realizadas y la lectura del manuscrito. A la Lic. María Delia Arena por contarme sus recuerdos de la excavación en El Molino y por las fotografías de las piezas de colección. A Manuel López Mateo por la colaboración en el remontaje de fragmentos y el relevamiento de la colección. A Raúl González Dubox por el dibujo de los perfiles de las vasijas de la tabla 4. A los evaluadores anónimos que con sus sugerencias contribuyeron a darle mayor claridad al trabajo.

\section{Notas}

1 El conjunto recuperado por González, luego de haber sufrido una serie de traslados, fue depositado en el Laboratorio de Análisis Cerámico de la Facultad de Ciencias Naturales y Museo de La Plata, donde se encuentra actualmente.

2 Este fechado es uno de los más tempranos para los sitios tardíos del Valle de Hualfín. Sin embargo, es necesario aclarar que fue realizado en la década del '70, cuando aún no existían las comparaciones interlaboratorio. Como ha señalado Wynveldt (2007), el mismo González advirtió acerca del peligro de aceptar estos fechados, que en este como en otros casos contradicen la secuencia arqueológica propuesta en función de los contextos arqueológicos (González y Cowgill 1975), que fue la evidencia que finalmente utilizó para ubicar al sitio en las fases II y III de Belén.

3 Esta vasija fue traída por la expedición, pero se halla perdida.

\section{Bibliografía citada}

\section{A.A.V.V}

1966. Primera Convención Nacional de Antropología. Instituto de Antropología, Facultad de Filosofía y Humanidades, Universidad Nacional de Córdoba.

Balfet, H., M. F. Fauvet-Berthelot y S. Monzon 1992. Normas para la descripción de vasijas cerámicas. México, Centre d'etudes Mexicaines et Centroaméricaines. 
García Mancuso, R. y M. E. Iucci

2008. Entierro infantil en un contexto doméstico (El Molino, Puerta de Corral Quemado, Catamarca). Resúmenes del XV Congreso de la Asociación Latinoamericana de Antropología Biológica, La Plata (Formato digital).

González, A. R.

1974. Arte, estructura y arqueología. Análisis de figuras duales y anatrópicas del N. O. argentino. Nueva Visión. Colección Fichas 35, Buenos Aires.

González, A. R. y G. L. Cowgill

1975. Cronología arqueológica del Valle de Hualfín, Pcia. de Catamarca, Argentina. Obtenida mediante el uso de computadoras. Actas del Primer Congreso de Arqueología Argentina: 383395.

Marchegiani, M. y C. Greco

2007. Tecnología, estilo y cronología de la cerámica ordinaria de Rincón Chico, Valle de Yocavil, Catamarca. Resúmenes ampliados del XVI Congreso Nacional de Arqueología Argentina. T. II: 201-206.

Menacho, $\mathrm{K}$.

2001. Etnoarqueología de trayectorias de vida de vasijas cerámicas y modo de vida pastoril. Relaciones de la Sociedad Argentina de Antropología XXXVI: 119-144.

Nelson, B.

1985. Reconstructing Ceramic Vessels and Their Systemic Contexts. Decoding Prehistoric Ceramics (ed. B. Nelson), pp. 310-329. Southern Illinois University Press, Carbondale.

Orton, C., P. Tyers y A. Vince.

1997. La cerámica en Arqueología. Crítica, Barcelona.

Rice, $\mathrm{P}$.

1987. Pottery Analysis: a Sourcebook. University of Chicago Press, Chicago.

Rye, O.S.

1981. Pottery Technology. Principles and reconstruction. Manuals on Archaeology 4. Taraxacum, Washington.

Sempé, M. C.

1999. La cultura Belén. Actas del XII Congreso Nacional de Arqueología Argentina. T. II: 250-258.

Senior, L. M. y D. P. Birnie, III

1995. Accurately estimating vessel volume from profile illustrations. American Antiquity, Vol. 60, $\mathrm{N}^{\circ} 2: 319-334$.

Shepard, A. O.

1956. Ceramics for the archaeologists. Carnegie Institution of Washington, Washington D. C.

Skibo, J.

1992. Pottery Function. A use - alteration perspective. Plenum Press, New York and London. 
Sinopoli, C. M.

1991. Approaches to Archaeological Ceramics. Plenum. Press, New York.

Smith, M. F., Jr.

1988. Function from whole vessel shape: a method and an application to Anasazi Black Mesa. American Anthropologist, Vol. 90, № 4: 912-923.

Weisser, $\mathrm{W}$.

1924. Diario de campo inédito de la expedición a Puerta de Corral Quemado. Colección Muñiz Barreto, Museo de La Plata.

Wolters, F.

1924. Libreta de campo inédita de la expedición a Puerta de Corral Quemado. Colección Muñiz Barreto, Museo de La Plata.

Wynveldt, F.

2007. Funcionalidad y cronología en un sitio del Período de Desarrollos Regionales (Loma de los Antiguos, Depto. de Belén, Prov. de Catamarca). Tesis doctoral inédita, Facultad de Ciencias Naturales y Museo, UNLP.

Wynveldt, F. y B. Balesta

2009. Paisaje sociopolítico y beligerancia en el Valle de Hualfín (Catamarca, Argentina). Antípoda $\mathrm{N}^{\circ}$ 09: 143-168.

Zagorodny, $\mathrm{N}$.

1996. Un estudio tecnológico sobre la alfarería doméstica en el Temprano. Actas y memorias del XI Congreso Nacional de Arqueología Argentina. $11^{\circ}$ Parte. Revista del Museo de Historia Natural de San Rafael. Tomo XXIII 1/4.133-143. Mendoza.

Zagorodny, N. y B. Balesta

1999. La construcción de grupos de referencia como herramienta en la investigación ceramológica. Actas del XII Congreso Nacional de Arqueología Argentina. T. II: 55-62. 